\title{
Local Phenol Application Versus Excision with Modified Primary Closure Technique in Pilonidal Sinus Disease: A Comparative Study
}

\author{
Adel Morad Abdallah ${ }^{1}$, Mohammed Abd-Alaal Mohammed ${ }^{1}$, Radwa Mamdouh El-Sabban ${ }^{2}$ \\ ${ }^{1}$ General Surgery Department, Faculty of Medicine, October 6 University, Giza, Egypt \\ ${ }^{2}$ Anatomy Department, Faculty of Medicine, October 6 University, Giza, Egypt
}

Email address:

Adel_morad1313@yahoo.com(A.M. Abdallah)

\section{To cite this article:}

Adel Morad Abdallah, Mohammed Abd-Alaal Mohammed, Radwa Mamdouh El-Sabban. Local Phenol Application Versus Excision with Modified Primary Closure Technique in Pilonidal Sinus Disease: A Comparative Study. Advances in Surgical Sciences.

Vol. 6, No. 1, 2018, pp. 20-26. doi: 10.11648/j.ass.20180601.14

Received: April 24, 2018; Accepted: May 10, 2018; Published: May 31, 2018

\begin{abstract}
Background: Different procedures are practiced nowadays for management of pilonidal sinus disease (PSD), ranging from the minimally invasive techniques to the complex flap techniques. Each procedure has its own advantages and drawbacks in terms of patient's satisfaction, follow up and recurrence rate. Local phenol application into the sinus track was practiced with encouraging results. The limited excision and modification of the primary closed technique has shown both low wound dehiscence and recurrence rates. The objective of this study is to evaluate and compare the local application of phenol $80 \%$ in the pilonidal sinus tracks after minimal debridement with the limited excision and modified primary closure technique. Methods: 52 patients suffering from chronic pilonidal sinus disease were divided equally into 2 groups. Patients in group I were managed with local phenol application under local anesthesia. In group II, the patients were operated upon by limited excision of the skin bearing the sinus pits and the underlying granulation tissue with modified primary closure technique using the gluteus maximus fasciae to close the cavity left followed by closure of the subcutaneous tissue and skin with leaving a suction drain inside. Results: The median duration of phenol applications procedure was $20 \pm 11$ minutes versus $41 \pm 13$ minutes in the modified primary closure technique. There was a significant difference between both groups as regards the duration of pain killers' use. By 5 weeks, signs of complete healing were shown in 22 patients $(84.5 \%)$ of the phenol group, versus 25 patients (96.2\%) in the surgery group with no statistic difference between both. The recurrence of PSD in the phenol group was detected in 2 cases $(7.7 \%)$ while it was one case $(3.8 \%)$ in the surgery group $(p=0.163)$. Conclusion: both procedures are simple, less surgically demanding, having simple postoperative care, low complication and recurrence rates, early recovery and good patient satisfaction.
\end{abstract}

Keywords: Phenol, Primary Closure Technique, Pilonidal Sinus, Gluteus Maximus Fascia

\section{Introduction}

Pilonidal sinus disease (PSD) is a common chronic inflammatory disease affecting the subcutaneous tissue of the sacrococcygeal area. It commonly affects young men. The disease usually presents itself in natal cleft with chronic recurrent discharge from a single or multiple orifices that are difficult to heal. The presumed etiology is either congenital or acquired. However the acquired causes are the most common [1]. The disease is commonly seen among young hairy men with prolonged sitting jobs [2]. As there is no standard treatment up till now for PSD, and due to its high recurrence rate, many studies on pilonidal sinus treatment are developing every now and then, trying to reach the optimum way of management. Surgeries for PSD ranged from the simple outpatient procedures (minimally invasive) to the complex flap techniques. Each of them has its advantages, complication and recurrence rates with different patient's satisfaction [3]. According to the literature, $12-22 \%$ of the patients may experience postoperative complications and $10 \%$ may experience recurrence [4]. The ideal treatment should include minimum tissue excision with minimal 
scarring, short hospital stay, a rapid cure and lower recurrence rate that allowed patients to return rapidly to normal activity, with minimal morbidity and low complication rate. Thus, minimally invasive treatments such as sinus pits excision, with mechanical and chemical clearance of the sinus tract became popular [5]. Phenol (carbolic acid) has antiseptic, anesthetic and strong sclerotic properties. Phenol treatment is considered one of the current popular minimally invasive options to treat pilonidal sinus. It can be used both in liquid or crystallized form [6].

Other surgical techniques for PSD are practiced and they vary in the way of dealing with the wound left after surgical excision of the sinus (with lay open, closed, modified closed or flap techniques), yet none of them were proposed as the most effective procedure [7].

Although some studies announced that the outcome of repair with flap is better, others suggested that primary closure method have a recurrence rate ranges from $0-42 \%$, however, this rate have been recently improved [8, 9]. A Modification of the primary closure technique was introduced by Sukru, et al [10]. They used the strong gluteus maximus fascia on both sides to close the cavity. They stated that the technique was more convenient than the ordinary primary closure with a lower recurrence and wound dehiscence rates.

The objectives of this study is to evaluate and compare the local application of phenol $80 \%$ in the pilonidal tracks after minimal debridement with the limited excision and modified primary closure technique.

\section{Patients and Methods}

42 patients suffering from PSD were the target of this study in October 6 university hospital in the period from 2012 to 2016. The patients were randomly classified into 2 groups each involved 21 patients; group I for phenol $80 \%$ application technique and group II for modified primary closure technique. Inclusion criteria involved any patient with chronic symptomatic pilonidal sinus disease with or without previous line of management (the new and recurrent cases). Exclusion criteria involved those who have acute pilonidal abscess, concomitant medical illness affecting the hemostatic process, or affecting immunity. The study protocol was approved by the Ethical Committee of the faculty of medicine of October 6 university. The procedures were fully explained to the patients in both groups and written consents were taken. Patients in group II required routine preoperative laboratory investigations while those in group I managed under local anesthesia and did not require routine investigations.

All patients in the study were operated upon in October 6 university hospital by the same surgical teams

Patients in Group I scheduled for local phenol 80\% application. The technique of phenol application was started with the patient in prone position with separation of the natal cleft using adhesive tapes to explore the whole sinus openings. The procedure was done under local anesthesia using Lidocaine injections in the pilonidal area. To avoid the injurious effect of phenol, the normal skin surrounding the sinus openings was protected either by using thick layer of Vaseline ointment or applying a DuoDERM ${ }^{\circledR}$ patch (ConvaTec) with covering and isolation of the anus with a dressing pad. The sinus pits were one or two millimeters circumferentially excised with a fine blade. Using a curved clamp the sinus pits were dilated and hair, debris and granulation tissue were removed from the sinus tract and the tract is curetted using spoon curette and irrigated using normal saline. The phenol was applied inside the sinus track by means of intra-venous cannula $(18 \mathrm{G})$ and syringe (figure 1). A suction catheter was used during the phenol introduction to suck any phenol comes out from the sinuses to avoid skin irritation. The phenol was left inside the track for 2 or 3 minutes and then squeezed out. In cases of big tracks the applications of phenol was repeated twice or thrice. The procedure ended with covering the sinus area with sterile gauze and the patients were discharged immediately. Regular dressings were followed thereafter. Some patients with unsatisfactory outcome were necessitated repeated phenol application settings. Patients in group II were scheduled for excision with modified primary closure technique. The procedure was done under regional or general anesthesia with the patient in prone position. The technique involved limited resection of the involved skin containing all sinus pits using a narrow elliptical incision. All the unhealthy sinus granulation tissue was included in the ellipse with preservation of the nearby normal tissues. Proper irrigation of the dead space left with hydrogen peroxide and normal saline. Dissection of the deep fascia covering both gluteus maximus muscles from the subcutaneous tissue layer on both sides of the ellipse was done using electro-cautery. The cavity was closed, after proper hemostasis, using PDS (Polydioxanone) 2/0 sutures to suture the gluteus maximus fascia on one side to the presacral fascia in midline to the gluteus maximus fascia on the other side in an interrupted manner forming from 4 to 7 sutures, about $1 \mathrm{~cm}$ apart, according to the length of the ellipse (figures $2 \& 3$ ). On tying the sutures the 2 glutei were approximated to the mid line forming a flap that fill the dead space and properly supports the wound. PDS was used to get the combination of an absorbable suture and extended wound support (up to six weeks). Suction drain was left on the approximated fascia in all patients. Next, polygycol $2 / 0$ sutures were used to suture the superficial fascial layer by interrupted sutures from the right to the left side of the ellipse in 2 layers. The skin was closed in subcuticular manner. Drains were removed once the outcome reached $<20 \mathrm{cc}$.

Follow up of the patients in group I involved operative time, postoperative pain, infection, duration of healing and sinus disease recurrence.

Follow up of the patients in group II included operative time, hospital stay, postoperative pain, wound infection, dehiscence and sinus disease recurrence.

Data analysis was performed using the Statistical Package for the Social Sciences (SPSS) 20.0 software and $p<0.05$ was considered statistically significant. 


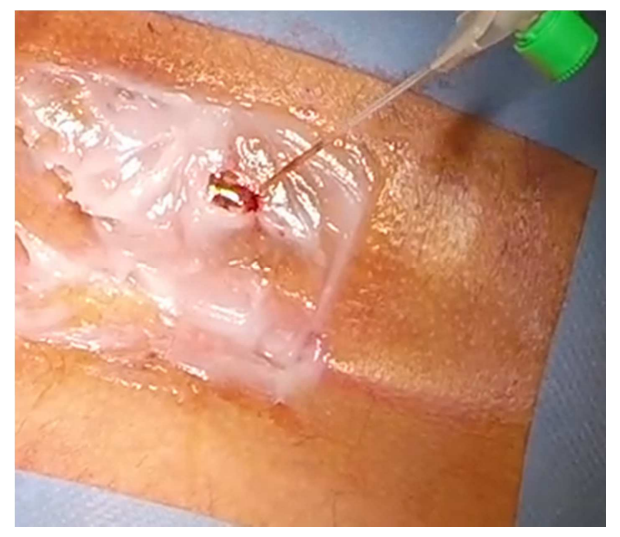

Figure 1. Technique of phenol application.

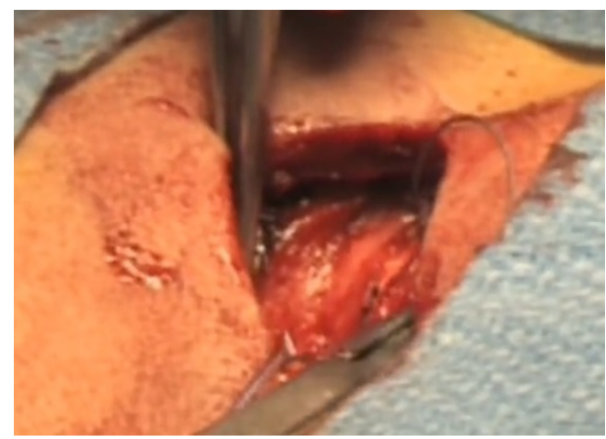

Figure 2. Suturing the gluteus fascia to pre-sacral fascia.

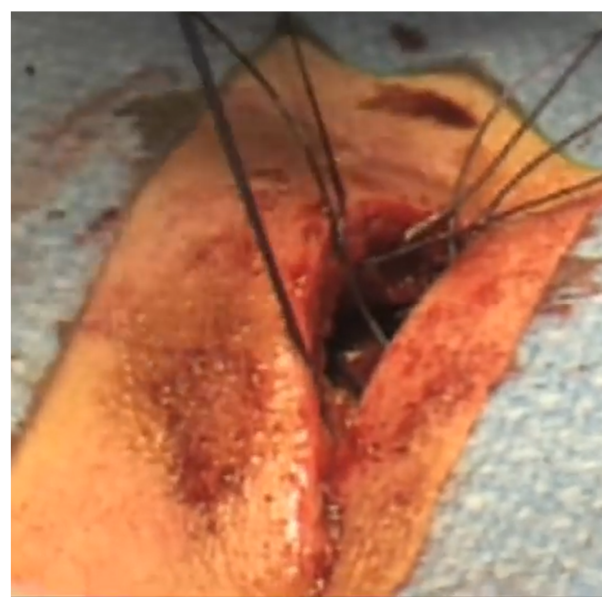

Figure 3. Hanging the gluteus maximus fasciae on both sides.

\section{Results}

52 patients with chronic pilonidal sinus diseases filling the criteria of selection were enrolled in this study in October 6 university hospital. They were equally and randomly distributed into 2 groups. Group I managed with local phenol application and group II with limited excision and modified primary closure technique.

\subsection{The Patients’ Demographic Data}

Age and sex distribution in both groups were listed in table 1. The median age in group I was $28 \pm 9$ years while it was $31 \pm 7$ in group II.

\subsection{Characters of PSD}

In group I, the characteristics of pilonidal sinus diseases among the patients were, de novo in 19 cases (73\%), recurrent once in 5 cases $(19.2 \%$ ) (Following lay open technique in 4 and simple closed technique in 1 case) and recurrent twice in 2 cases $(7.7 \%)$; one of them followed simple closed and the other lay open technique (Table 2). Also single sinus pit existed in 17 cases $(65.3 \%), 2$ pits in 5 cases $(19.2 \%)$ and more than 2 pits in 4 cases $(15.3 \%)$. In group II, the de novo pilonidal sinus cases were 17 cases $(65.4 \%)$, the single recurrence was in 6 cases $(23 \%)$; (Followed simple closed technique in 3 cases and lay open technique in 3 cases) and twice recurrence in 3 cases $(11.5 \%)$; both followed lay open procedures. Also in group II, single sinus pit was detected in 15 cases $(57.7 \%), 2$ pits in 8 cases $(30.7 \%)$ and more than 2 pits in 3 cases $(11.5 \%)$. In group I, 16 cases $(61.5 \%)$ required single phenol application session, 6 cases $(23 \%)$ required 2 nd application session and 4 cases $(15.3 \%)$ required 3 rd session.

\subsection{Duration of the Procedures}

There was a significant difference as regards the duration of the 2 procedures. The median duration of phenol applications procedure was $20 \pm 11$ minutes versus $41 \pm 13$ minutes in the modified primary closure technique (Table 3 ).

\subsection{Hospital Stay}

In the group treated with MPC technique, it was $1 \pm 0.7$ days, whereas patients in the group treated with phenol application were discharged immediately after the procedure; hence, shorter length of hospital stays $(\mathrm{p}<0.001)$ (Table 3$)$.

\subsection{Short Term Follow up}

Short term follow of both groups included pain evaluation, early complications and wound healing time.

\subsubsection{Post-Operative Pain}

Patients in group I properly responded well to nonsteroidal anti-inflammatory drugs (NSAIDS) on regular doses for the first 48 hours with increased pain free periods and lower doses of NSAIDS thereafter. Patients in the surgery group experienced more pain in the first 48 hours that necessitated injection of narcotic analgesics (Pethidine) in 17 patients $(65.3 \%)$ with lesser pain free periods than phenol group, while, the remaining 9 patients $(34.6 \%)$ responded well to NSAIDS. The use of NSAIDS in the surgery group continued till the end of the first week postoperatively in 22 patients $(84.7 \%)$ and for 10 days in 4 patients $(15.3 \%)$ (Table 4).

\subsubsection{Early Complications}

Table 5 demonstrated the early postoperative complications among both groups. In the phenol group, 2 patients $(7.7 \%)$ had localized cellulitis in the surrounding skin which was managed conservatively with topical and oral antibiotics. Also, 10 patients (38.5\%) in the phenol group had 
continuous discharge from the sinus pits for 3 weeks postoperative, 6 of them responded well to another phenol application session with the same technique with healing in all cases in 2-3 weeks. The other 4 patients $(15.3 \%)$ had responded well to second and third phenol application session with healing within 2 weeks after the third session. The early complications in group II included wound infection in 3 cases $(11.5 \%)$ and hematoma in one patient (3.8\%). 2 cases of wound infection were responded well to antibiotics and one responded to wound drainage. The patient who developed hematoma resolved with wound drainage.

\subsubsection{Duration of Healing}

The duration of healing varies between both groups (Table $6)$. In phenol group the discharge stopped before 3 weeks in 16 patients with complete healing detected by 5 weeks duration. The 6 cases in them the re do procedures were done; signs of complete healing were detected in within 2-3 weeks following repetition of the procedure. In group II, signs of complete healing of the wounds were detected in 14 cases $(53.8 \%)$ within 3 weeks, 7 cases $(30.7 \%)$ after 4 weeks and 4 cases $(15.3 \%)$ after 5 weeks. There was one case (3.8\%) of wound dehiscence belonged to one of those needed postoperative wound drainage with signs of complete healing after 7 weeks.

\subsection{Recurrence of PSD}

The recurrence of PSD in the phenol group was detected in 2 cases $(7.7 \%$ ) (Table 7) in a median follow up of $18 \pm 3$ months duration. The recurrent cases included one with single phenol session, and the other case with 2 phenol sessions after 19 and 21 weeks respectively. One case (3.8\%) in group II showed recurrence of PSD after 7 months duration preceded with pilonidal abscess formation, in a median follow up $19 \pm 6$ months.

Table 1. Patients' demographic data.

\begin{tabular}{llll}
\hline \multirow{2}{*}{ Patient character } & Group I & Group II & \multirow{2}{*}{ p } \\
\cline { 2 - 3 } & $\mathbf{n = 2 6 ( \% )}$ & $\mathbf{n = 2 6}(\mathbf{\%})$ & 0.241 \\
\hline Age (years) & $28 \pm 9$ & $31 \pm 7$ & \\
Sex & & & 0.352 \\
- Male & $18(69.2 \%)$ & $20(77 \%)$ & 0.421 \\
- Females & $8(30.8 \%)$ & $6(23 \%)$ & \\
\hline
\end{tabular}

Table 2. Characters of PSD.

\begin{tabular}{llll}
\hline $\begin{array}{l}\text { Pilonidal sinus } \\
\text { disease }\end{array}$ & Group I & Group II & \multirow{2}{*}{$\mathbf{p}$} \\
\cline { 2 - 3 } $\mathbf{n = 2 6 ( \% )}$ & $\mathbf{n = 2 6 ( \% )}$ & \\
\hline - De-novo cases & $19(73 \%)$ & $17(65.4 \%)$ & 0.127 \\
- Recurrent once & $5(19.2 \%)$ & 6 cases $(23 \%)$ & 0.231 \\
- Recurrent twice & $2(7.7 \%)$ & $3(11.5 \%)$ & 0.353 \\
- Single sinus pit & $17(65.3 \%)$ & $15(57.7 \%)$ & 0.129 \\
- 2 pits & $5(19.2 \%)$ & $8(30.8 \%)$ & 0.331 \\
$->2$ pits & $4(15.3 \%)$ & $3(11.5 \%)$ & 0.453 \\
\hline
\end{tabular}

Table 3. Duration of the procedure and hospital stay.

\begin{tabular}{|c|c|c|c|}
\hline & Group I & Group II & P value \\
\hline & $(n=26)$ & $(n=26)$ & P value \\
\hline Duration of the procedure (minutes) & $17 \pm 11$ & $41 \pm 13$ & $<0.0001$ \\
\hline Hospital stay (day) & 0 & $1 \pm 0.7$ & $<0.001$ \\
\hline
\end{tabular}

Table 4. Postoperative pain and pain killers' use.

\begin{tabular}{llll}
\hline Pain response & Group I & Group II & \multirow{2}{*}{ P } \\
\cline { 2 - 3 } & $\mathbf{( n = 2 6 )}$ & $\mathbf{( n = 2 6 )}$ & \\
\hline - NSAIDS (n\%) & $26(100 \%)$ & $9(33.3 \%)$ & $<0.001$ \\
- Narcotics (Pethidine) & 0 & $17(66.7 \%)$ & $<0.0001$ \\
- Duration of analgesic & & & \\
- 2 days (n\%) & $26(100 \%)$ & 0 & $<0.0001$ \\
- 7 days $(\mathrm{n} \%)$ & 0 & $22(84.7 \%)$ & $<0.0005$ \\
- 10 days $(\mathrm{n} \%)$ & 0 & $4(15.3 \%)$ & $<0.001$ \\
\hline
\end{tabular}

Table 5. Early postoperative complications.

\begin{tabular}{llll}
\hline & Group I & Group II & \multirow{2}{*}{ P } \\
\cline { 2 - 3 } & $\mathbf{n = 2 6}$ & $\mathbf{n = 2 6}$ & \\
\hline Localized cellulitis & $2(7.7 \%)$ & 0 & 0.01 \\
Continuous discharge & $10(38.5 \%)$ & 0 & 0.001 \\
Wound infection & 0 & $3(11.5 \%)$ & 0.001 \\
Hematoma & 0 & $1(3.8 \%)$ & 0.02 \\
Total & 12 & 4 & 0.106 \\
\hline
\end{tabular}

Table 6. Healing of the wounds.

\begin{tabular}{llll}
\hline \multirow{2}{*}{ Time of healing } & Group I & Group II & \multirow{2}{*}{ P } \\
\cline { 2 - 3 } & $\mathbf{n = 2 6}$ & $\mathbf{n = 2 6}$ & \\
\hline 3 weeks & $16(61.5 \%)$ & $14(53.8 \%)$ & 0.261 \\
4 weeks & - & $7(27 \%)$ & \\
5 weeks & $6(23 \%)$ & $4(15.3 \%)$ & 0.114 \\
7 weeks & $4(15.3)$ & $1(3.8 \%)$ & \\
Total & $26(100 \%)$ & $26(100 \%)$ & \\
\hline
\end{tabular}

Table 7. The recurrence of PSD.

\begin{tabular}{llll}
\hline & Group I & Group II & \multirow{2}{*}{ P } \\
\cline { 2 - 3 } & $\mathbf{n = 2 6}$ & $\mathbf{n = 2 6}$ & \multirow{2}{*}{0.163} \\
\hline Recurrence & $2(7.7 \%)$ & $1(3.8 \%)$ & \\
Time of recurrence & -19 weeks & 28 weeks & \\
\hline
\end{tabular}

\section{Discussion}

PSD has many lines of treatment vary from the simple minimally invasive techniques to the complex flap techniques, however debates still exists about which is the ideal for the patient $[11,12]$. Complications and recurrence are the most important problems encountered after management of PSD. Investigations to reach an efficient and safe method that can reduce the risk of recurrence and complications to a minimum and modifications of current methods are still being conducted [1]. The ideal method chosen should be simple, with minimal pain, has a short or no hospital stay with minimal postoperative care of the wound. It should also allow rapid return to work with normal activity, have a low recurrence rate and low cost [13].

Many surgical procedures are being used in treatment of PSD with different reported outcomes. The procedures in common use are excision with lay open, excision with closed or modified closed technique and flap procedures. Different studies have showed superiority of flap repair to primary closure techniques $[14,15]$. Although, some literatures stated that methods using flaps are considered better in terms of complication and recurrence, recently primary closure methods are reported to have good outcomes also [16, 17]. A recent study done by Sukru et al, who modified the primary 
closure technique with better obliteration of the dead space after pilonidal sinus excision showed successful result but increases the duration of operation [10]. Recently, the minimally invasive techniques have been developed for the treatment of PSD, including the local application of crystallized phenol that is reported to be simple, outpatient and inexpensive method with successful outcomes $[18,19]$. Phenol is a chemical compound known carbolic acid. It presented in two forms the liquid and crystallized form. It produces irritation of the inner wall of the pilonidal sinus track with formation of granulation tissue and deposition of fibrous tissue leading to contraction and closure of the sinus cavity or track [5].

In the present study comparison of one minimally invasive technique, which is the local phenol application, with modification of primary closure technique in terms of healing, complications and recurrence rates was evaluated. The operative time in both procedures was statistically different $(17 \pm 11$ minutes in phenol group versus $41 \pm 13$ minutes in the surgery group with $\mathrm{P}<0.0001$ ) although both times are still lower than other flap procedures. The necessity of pain killers varied significantly among the 2 groups with more pain free and lesser needs for analgesics among the phenol group than the modified primary closure technique. There was a significant difference among the 2 groups regarding the hospital stay as the patients in the phenol group were discharged immediately, while the median hospital stay in the surgery group was $1 \pm 0.7$ days.

The early complications in both groups were found to be mild and easily managed conservatively with no significant difference in term of the total cases showed complications ( $p$ $=0.106)$. The healing in both group showed no significant difference. In the phenol group healing was detected in 22 patients versus 25 patients in the surgery group within 5 weeks duration. The recurrence of PSD showed no significant difference between both groups $(p=0.163)$. The recurrence in the phenol group was detected in 2 cases $(7.7 \%)$ and in the surgery group was one case $(3.8 \%)$ in a median follow up of $18 \pm 3$ months and $19 \pm 6$ months respectively. The recurrent cases in the phenol group were as follow; one case that underwent second session of phenol application, and one of the primary healed cases. The time of recurrence in the last case was at 19 and 21 weeks. The recurrent case in the surgery group was detected after 7 months and preceded with pilonidal abscess formation. All the recurrent cases were presented preoperatively with more than 2 sinus pits. In comparison with literatures that used phenol application in PSD, recurrence of 1.9\% (1.1-2.6\%) was observed in patients at 12 months and 14.1\% (11.8$16.5 \%$ ) at 24 months which was consistent with the results of the present study $[6,20]$. In a recent study used local phenol application in PSD, announced an overall cure rate of $88 \%$ and stated that the procedure was simple, safe, fast and comfortable for the patients and it recommends the use of phenol in PSD [21]. Another study assessed the use of phenol with endoscopic management of PSD. The study stated that it was safe, tolerable, and achieved fast and durable healing with no recurrence over an average of 22 months of followup [22]. A recent study compared the primary closure technique with the modified primary closure technique showed a statistically significant difference in recurrence rate between the two groups, ( $4 \%$ versus $0 \%$ respectively, $\mathrm{p}<$ $0.05)$. Also, they observed statistically significant difference between the two groups about the dehiscence of incision ( $p<$ 0.05 ). The study explained these differences by the proper and comfortable closure of the dead space left after excision of the sinus track [9]. The dead space at the operation site and both subcutaneous and skin tensions are the major causes of complications such as hematoma, infection and dehiscence that follow pilonidal sinus surgery, and responsible for recurrences in most cases [23, 24]. Moreover, the dehiscence of the incision may occur because of tissue tension after postoperative day 15 , when the incision sutures are removed.

In the present study, limited excision of the unhealthy pilonidal skin only, leaving the normal surrounding skin was done. The dead space was closed by suturing the gluteus maximus fasciae on both sides with the presacral fascia, followed by closure of the subcutaneous tissue. This pattern of closure will keep supporting the tissue tension, thus, the patients will experience less dehiscence of the incision and hence less recurrence in comparison to the classic primary closure technique. By review of literatures concerned with the closed method of treatment of PSD, recurrence of $1.0 \%$ (0.6-1.4\%) was observed in patients at 12 months and $1.6 \%$ $(1.1-2.1 \%)$ at 24 months $[25,26]$. Data on recurrence and follow-up of 530 patients with PSD treated by partial closure technique showed a recurrence of $2.8 \%(1.2-4.4 \%)$ in patients at 12 months, and 5.1\% (2.8-7.3\%) at 24 months [27, $3]$. Karydakis and Bascom cleft lift techniques showed low recurrence rates in the literatures among the flap technique used in PSD. The recurrence rates were 1.5\% (0.8-2.2\%) at 12 months, and $2.4 \%(1.4-3.3 \%)$ at 24 months [3, 28, 29]. However although these flap techniques have had low recurrence rates, in comparison to other procedures, they are surgically demanding procedures, with longer operative times, delayed recovery periods and the presence of large scar, which generally causes an unpleasant esthetic look for the patients. So these procedures should be resorted to the recurrent cases and those having excess tissue loss in the pilonidal area. Recently, the surgical management PSD went towards the minimal invasive techniques as sinus pit-picking technique, endoscopic management and phenol [5, 30, 31]. Finally, in determining the treatment method in PSD, the preference of the surgeon, patient's needs and extend of the disease are important factors to be taken into consideration. Each method has a certain recurrence rate, and patient satisfaction and none of them is used as the gold standard procedure.

\section{Conclusion}

In this study, 2 simple procedures for PSD were used, one of them; the phenol application considered a minimally invasive technique done under local anesthesia and the other 
was modified primary closure technique. Both procedures, compared to others, are considered simple, less surgically demanding, having short operative time and hospital stay. In addition, both have simple postoperative care, low complication and recurrence rates, early postoperative recovery and good patient satisfaction. However, follow up is required for better evaluation of the two procedures on long term

\section{References}

[1] K. Arslan, S. Said Kokcam, H. Koksal, E. Turan, A. Atay, O. Dogru: Which flap method should be preferred for the treatment of pilonidal sinus? A prospective randomized study. Tech. Coloproctol. 2014; 18:29-37.

[2] Harlak A, Mentes O, Kilic S, Coskun K, Duman K, Yilmaz F. Sacrococcygeal pilonidal disease: analysis of previously proposed risk factors. Clinics (Sao Paulo). 2010; 65:125-131.

[3] V. K. Stauffer, M. M. Luedi, P. Kauf, M. Schmid, M. Diekmann, K. Wieferich, B. Schnüriger, D. Doll: Common surgical procedures in pilonidal sinus disease: A metaanalysis, merged data analysis, and comprehensive study on recurrence. Scientific Reports. 2018; 8:3058.

[4] Çağlayan K, Güngör B, Topgül K, Polat C, Çınar H, Ulusoy AN. Investigations of patient dependent factors effecting complications and recurrence in pilonidal sinus disease. Colon Rectum Hast Derg. 2011; 21: 103-8.

[5] Isik A, Eryılmaz R, Okan I, et al. The use of fibrin glue without surgery in the treatment of pilonidal sinus disease. Int. J. Clin. Exp Med. 2014; 7:1047-1051.

[6] Akan K, Tihan D, Duman U, Ozgun Y, Erol F, Polat M. Comparison of surgical Limberg flap technique and crystallized phenol application in the treatment of pilonidal sinus disease: a retrospective study. Ulus Cerrahi Derg. 2013; 29:162-166.

[7] Ertan T, Koc M, Gocmen E, Aslar AK, Keskek M, Kilic M. Does the technique alter quality of life after pilonidal sinus surgery? Am. J. Surg. 2005; 190:388-392.

[8] Kaya B, Uçtum Y, Șimșek A, Kutaniș R. Treatment of pilonidal sinus with primary closure. A simple and effective method. Colon Rectum Hast Derg. 2010; 20: 59-65.

[9] Küçükkartallar T, Tekin A, Vatansev C, Aksoy F, Erenoğlu B. The comparison of the results of different operative techniques for pilonidal sinus disease. Genel. Tip. Derg. 2007; 17: 95-7.

[10] Sukru Arslan, Erdem Karadeniz, Gurkan Ozturk, Bulent Aydinli, Muhammed Cagri Bayraktutan, Sabri Selcuk Atamanalp. Modified Primary Closure Method for the Treatment of Pilonidal Sinus. Eurasian Journal of Medicine. 2016; 48: 84-9.

[11] Gidwani AL, Murugan K, Nasir A, Brown R. Incise and lay open: an effective procedure for coccygeal pilonidal sinus disease. Ir. J. Med. Sci. 2010; 179:207-210.

[12] Aydede H, Erhan Y, Sakarya A, Kumkumoglu Y. Comparison of three methods in surgical treatment of pilonidal disease. ANZ J. Surg. 2001; 71:362-364.
[13] Kuzu MA. Commentary. Colorectal Disease. 2008; 10:651652 .

[14] Mahdy T: Surgical treatment of the pilonidal disease: primary closure or flap reconstruction after excision. Disease Colon Rectum. 2008; 51:1816-1822.

[15] Ersoy OF, Karaca S, Kayaoglu HA, Ozkan N, Celik A, Ozum $\mathrm{T}$ : Comparison of different surgical options in the treatment of pilonidal disease: retrospective analysis of 175 patients. Kaohsiung J. Med. Sci. 2007; 23:67-70.

[16] Doll D, Evers T, Matevossian E, Petersen S. Outcome of chronic pilonidal disease treatment after ambulatory plain midline excision and primary suture. Am. J. Surg. 2009; 197: 693-4.

[17] Dalenback J. Prospective follow-up after ambulatory plain midline excision of pilonidal sinus and primary suture under local anaesthesia-efficient, sufficient, and persistent. Colorectal Diseases. 2006; 8: 73-4.

[18] Dogru O, Camci C, Aygen E, Girgin M, Topuz O: Pilonidal sinus treated with crystallized phenol: an eight-year experience. Disease Colon Rectum. 2004; 47:1934-1938.

[19] Aygen E, Arslan K, Dogru O, Basbug M, Camci C: Crystallized phenol in non-operative treatment of previously operated, recurrent pilonidal disease. Dis Colon Rectum. 2010; 53:932-935.

[20] Oueidat D., Dirani R., Assi M., Shams T., Jurjus A.: 25 years' experience in the management of pilonidal sinus disease. Open Journal of Gastroenterology. 2014; 4-5.

[21] Yuksel ME. Pilonidal sinus disease can be treated with crystallized phenol using a simple three- step technique. Acta Dermatovenerol. Alp. Pannonica Adriat. 2017; 26 (1):15-17.

[22] Gecim I, Goktug U, Celasin H. Endoscopic Pilonidal Sinus Treatment Combined With CrystalizedPhenol Application May Prevent Recurrence. Diseases Colon Rectum. 2017; 60 (4): 405-407.

[23] Kaya B, Uçtum Y, Şimşek A, Kutaniş R. Treatment of pilonidal sinus with primary closure. A simple and effective method. Colon Rectum Hast Derg 2010; 20: 59-65.

[24] Karydakis GE. Easy and successful treatment of pilonidal sinus after explanation of its causative process. Aust N. Z J. Surg. 1992; 62: 385-9.

[25] Brusciano L. et al. D-shape asymmetric excision of sacrococcygeal pilonidal sinus with primary closure, suction drain, and subcuticular skin closure: an analysis of risk factors for long-term recurrence. Surg. Innov. 2015; 22, 143-148.

[26] Doll D., Matevossian E., Hoenemann C. \& Hoffmann S. Incision and drainage preceding definite surgery achieves lower 20-year long-term recurrence rate in 583 primary pilonidal sinus surgery patients. Patient info. 2013; 11, 60-64.

[27] Rahoma A. H. Pilonidal sinus: Why does it recur? Malays. J. Med. Health Sci. 2009; 5, 69-77.

[28] Doll D., Luedi M. M., Evers T., Kauf P., Matevossian E. Recurrence-free survival, but not surgical therapy per se, determines 583 patients' long-term satisfaction following primary pilonidal sinus surgery. Int. J. Colorectal Disease. 2015; 30, 605-611. 
[29] Shah A., Waheed A., Malik A. Recurrence rates in pilonidal sinus surgery: Comparison of two techniques (Karydakis Versus Conventional Open Excision). Pak. J. Med. Health Sci. $2009 ; 3,91-95$.

[30] Ehrl D, Choplain C, Heidekrueger P, Erne HC, Rau HG, Broer PN. Treatment Options for Pilonidal Disease. Am. Surg. 2017; $83(5): 453-457$.
[31] Giarratano G, Toscana C, Shalaby M, Buonomo O, Petrella G, Sileri P. Endoscopic Pilonidal Sinus Treatment: Long-Term Results of a Prospective Series. JSLS. 2017; 21 (3). 